\title{
La educación de jóvenes y adultos frente al desafío de los movimientos sociales emergentes en Argentina*
}

\section{María Teresa Sirvent}

Universidad de Buenos Aires, Facultad de Filosofía y Letras

\section{Introducción}

En primer lugar, deseo profundamente agradecer esta invitación de ANPEd para pronunciar esta conferencia. Brasil recibió a mi familia durante el exilio al que nos obligó la dictadura militar más cruenta de la Argentina, en los años 1976-1983. Nos brindó su calor humano, su protección y también la posibilidad de haber llevado acabo unas de las experiencias más rica de mi vida profesional, en el marco de la educación popular de jóvenes y adultos y la investigación participativa. Estoy siempre eternamente agradecida y en deuda por la fuente de aprendizajes que significó el pueblo brasileño y los debates e intercambios con nuestros colegas. Me marcaron para toda la vida.

Pido disculpas a los colegas brasileños por el foco de esta conferencia en la situación de Argentina. La complejidad de todo momento histórico y específi-

* Conferência pronunciada no Grupo de Trabalho Educação de Jovens e Adultos, durante a $27^{\mathrm{a}}$ Reunião Anual da ANPEd, realizada em Caxambu (MG), de 21 a 24 de novembro de 2004. camente la diversidad de las situaciones en América Latina hace imposible cualquier intento de generalización. ${ }^{1}$

El propósito de este artículo es presentar algunas reflexiones metodológicas en relación con la educación de jóvenes y adultos sobre la base de nuestras experiencias de educación popular e investigación participativa en Argentina. ${ }^{2}$ Estas reflexiones parten desde un abordaje de una psicología social que busca

${ }^{1}$ En la Conferencia Internacional de Sociología de la Educación (International Sociological Asociation/ Facultad de Filosofía y Letras, Universidad de Buenos Aires, Agosto 2004) se señaló no sólo la naturaleza diversa de estos movimientos sociales, sino incluso el carácter fallidamente abarcativo del término "movimientos sociales". Exposición de Luis Rigal en el panel "Construyendo puentes entre la producción de conocimientos y la práctica social".

${ }^{2}$ Programa de Investigación sobre Desarrollo Sociocultural y Educación Permanente: La Educación de Jóvenes y Adultos más allá de la Escuela. Dirección María Teresa Sirvent - Instituto de Investigaciones en Ciencias de la Educación, Facultad de Filosofía y Letras, Universidad de Buenos Aires. 
identificar los procesos que dan cuenta del procesamiento, del "impacto" de los hechos de la vida cotidiana en la construcción de nuestras visiones sobre la realidad. Es decir, desde una mirada de una psicología social que, como remarca Ana Quiroga, ${ }^{3}$ indaga la relación dialéctica entre el orden socio-histórico y los sujetos. Es mi deseo que al término de esta conferencia quede al menos el estímulo para un fructífero intercambio donde busquemos identificar los puntos en común y las diferencias con vuestras experiencias cotidianas.

La exposición abarcará dos ejes centrales:

1. Ubicar la educación popular de jóvenes y adultos en la Argentina, en su relación con los movimientos sociales en un proceso histórico a partir de la terminación de la dictadura militar y hasta nuestros días.

2. Plantear los desafíos y contradicciones del momento histórico presente para la educación popular de jóvenes y adultos en su relación con los movimientos sociales emergentes.

\section{La educación popular de jóvenes y adultos en la Argentina, en su relación con los movimientos sociales en un proceso histórico a partir de la terminación de la dictadura militar y hasta nuestros días}

Es obvio que es imposible hablar de educación popular de jóvenes y adultos en un vacío histórico. Es obvio asimismo que el encuadre histórico es una de las herramientas principales para intentar comprender los fenómenos actuales.

En mi caso personal y en el de muchos colegas, iniciamos trabajando en educación popular de jóvenes y adultos desde los principios de los años 1960,

${ }^{3}$ Exposición de Ana Quiroga en el panel inaugural de la III Jornada Latinoamericana de Psicología Social y V Jornada de Homenaje al Dr. Enrique Pichón Riviére, "Sujeto y conflicto social". Buenos Aires, 28 al 31 de Octubre de 2004. cuando la educación popular en Argentina entraba a jugar claramente como soporte de la construcción del conocimiento necesario para la elaboración de un proyecto popular del sujeto histórico del cambio social, que para muchos de nosotros era la clase obrera organizada en las zonas urbanas.

A partir de mediados de los 1960 y hasta fines del año 1983, muchos fueron los ríos de represión, sangre y muerte que corrieron por las calles de Argentina. Los golpes de estado sucesivos y la dictadura del 1976 fue acompañando a un proyecto económico del capitalismo universal en América Latina que fue destruyendo en Argentina su potencial industrial, debilitando la fuerza de la clase obrera organizada como sujeto negador del capitalismo. Las dictaduras militares en ese período también reprimieron y persiguieron a las experiencias de educación popular y a la formación de educadores populares y animadores socioculturales a través de la universidad. Éramos considerados parte de los cuadros subversivos que atentábamos en contra del status quo y de los intereses de los grupos dominantes. Sólo el retorno del peronismo al poder, en el corto lapso de 1973-1976, implicó la posibilidad de retomar nuevamente la perspectiva de una educación de jóvenes y adultos al servicio de la construcción del proyecto político de los sectores populares.

A partir de 1983, con el retorno a la democracia, distinguimos sobre la base de nuestras experiencias de investigación participativa y educación popular tres momentos o hitos históricos ${ }^{4}$ que fueron marcando diferentes intencionalidades de la educación popular de jóvenes y adultos hasta llegar al desafío del momento actual.

\section{Primer momento: 1984-1989}

Recién salidos de la dictadura, fuimos diagnosticando un campo desbastado en la sociedad civil; una

${ }^{4}$ Algunos aspectos de este encuadre histórico fueron mencionados en Sirvent (2003). 
aguda situación de "debilidad de la sociedad civil". 5 Aparecen fuertemente una serie de fenómenos que obturaban la posibilidad de una reconstrucción a pesar de la voluntad y la fuerza de reconstrucción de las organizaciones populares y de la búsqueda de la democratización de nuestras instituciones sociales y educativas.

El objetivo entonces de nuestras acciones de investigación social y de educación popular de jóvenes y adultos buscaba apoyar el fortalecimiento de la trama organizativa de los sectores populares y su constitución como sujetos políticos de la democracia. Siempre hemos concebido la investigación social y educativa con una doble intencionalidad: generar conocimiento científico a la vez comprometido con las luchas sociales por una sociedad más justa e igualitaria.

Fuimos detectando una serie de rasgos de la vida cotidiana y asociacional que operaban como obstáculos del fortalecimiento de la trama organizativa. Pudimos visualizar como una historia social y política del país y la cruenta dictadura militar no había pasado en vano: había dejado sus huellas en la forma en que pensábamos, sentíamos y actuábamos en nuestra vida cotidiana, en nuestra manera de "ver" la realidad, inhibiendo no sólo nuestras posibilidades de participar sino incluso, negándonos la posibilidad o ahogando en nosotros mismos el sentir la necesidad de participar. ${ }^{6}$ Cobraba realidad una histórica pero más que nunca vigente pregunta de Gramsci: ¿Cómo hacen las clases

${ }^{5}$ Es interesante señalar que a mi regreso a la Argentina encontré que la dictadura militar había cercenado de plano el campo de la educación popular y de la investigación social comprometida con una realidad de injusticia y discriminación. Desde mi perspectiva, nos habíamos convertido en el "furgón de cola de América Latina" en relación con estas perspectivas que buscaban articular la investigación, la participación y la educación (Exposición de María Teresa Sirvent en la Facultad de Filosofía y Letras de la Universidad de Buenos Aires, Octubre 1984).

${ }^{6}$ Nuestra perspectiva teórica en relación con el estudio de la participación como necesidad humana asume la diferenciación entre necesidades objetivas y subjetivas y presupone la determinación social de necesidades colectivas e individuales. Por necesidad dominantes para gobernar sin empleo de la fuerza? Obviamente, actuando sobre nuestras conciencias y nuestras maneras de representar, teorizar y pensar sobre nuestra vida cotidiana.

Así vimos emerger, en nuestras investigaciones y trabajos, frente a nosotros y en nosotros mismos:

a) La apatía participativa y el "no te metas".

b) El miedo carcomiendo cualquier pequeño impulso para la acción comprometida, que fue un "descubrimiento" en nuestras investigaciones.

c) El "olvido histórico" en términos de una historia cercenada y fragmentada como producto de la represión y del miedo. Como decía uno de los

subjetiva entendemos un estado de carencia sentido y percibido como tal por los individuos o grupos de individuos. Por necesidad objetiva nos referiremos a carencias de los individuos o grupos que pueden determinarse independientemente de la conciencia que de las mismas tengan los individuos afectados. La determinación objetiva de las necesidades se apoya en la existencia de desequilibrios que impiden el desarrollo pleno de las potencialidades humanas.

La necesidad que la gente siente, la necesidad subjetiva, puede o no coincidir con necesidades derivadas de situaciones objetivas que afectan la vida cotidiana de individuos y grupos. Los conceptos de necesidades subjetivas y objetivas se basan en la tradición marxista que distingue entre intereses subjetivos y objetivos. En una aproximación marxista, un interés es objetivo porque deriva de condiciones sociales que objetivamente afectan a los individuos y grupos independientemente de la conciencia o reconocimiento individual o grupal de dichas condiciones objetivas. Estas pueden ser observadas y "medidas" por estándares externos a la conciencia de los individuos. Desde la perspectiva objetiva, un individuo tiene interés en algo cuando es afectado por ese algo. La existencia del interés no es contingencia de la conciencia o reconocimiento del mismo por el individuo. Una persona o grupos de personas pueden estar afectados por algo ya sea que lo reconozcan o no. El interés es subjetivo porque se refiere a un estado psicológico en la mente de una persona que dice tener tal interés. Parte del desarrollo de la conciencia de clase en términos marxistas envuelve el proceso de “conversión" de los intereses objetivos en intereses subjetivos. Para más detalles, ver Sirvent (1999a). 
miembros vecinales de nuestros grupos de trabajo:" "Pero si nosotros mismos nos pusimos una tela emplástica en la cabeza..." "Nos han hecho un lavado de cerebro para tener miedo y no participar".

d) La internalización y validación como formas legítimas de hacer política institucional de mecanismos profundamente antiparticipativos: como el clientelismo, el internismo ${ }^{8}$ o la fragmentación continúa, el matonismo (una suerte de prácticas de terrorismo institucional a la manera del terrorismo de Estado) y la coaptación. ${ }^{9}$ Como señaló un miembro de una asociación vecinal en relación con el fenómeno de coaptación: “...el que te paga te posee....${ }^{10}$ Mecanismos que se "infiltraron" en las organizaciones populares y en nuestras universidades. En palabras de un líder vecinal: “...son mecanismos que se han hecho carne en nosotros...". 11

${ }^{7}$ Frases extraídas de Sirvent (1999a, p. 200-223).

${ }^{8}$ La palabra "internismo" se refiere al fenómeno de fragmentación o de ruptura de un grupo social frente a posiciones o puntos de vistas diferentes. Frente a un discenso se fractura el grupo o el movimineto y se forman las "internas" que obturan la posibilidad del debate o bien la aceptación del discenso sin ruptura del grupo o del movimiento.

${ }^{9}$ El término "coaptación" fue introducido por Philips Selznick en 1948 y alude al mecanismo usado por una organización a través del cual se incorpora la oposición para mantener su estructura y estabilidad. Este proceso es usado para absorber nuevos elementos en la estructura política o de liderazgo, como medio para prevenir amenazas a su estabilidad o existencia (véase Sirvent, 1999a, p. 14)

${ }^{10}$ Boletín Ida y Vuelta. Síntesis de las reuniones de análisis colectivo de la realidad cotidiana con representantes de Asociaciones Voluntarias y miembros de Movimientos Sociales de la Villa 15 ("Favella" en la periferia sur de Buenos Aires). Estas reuniones son parte de las instancias participativas de retroalimentación en nuestros procesos de investigación social.

${ }^{11}$ Frase extraída de Sirvent (2004).
Así fuimos testigos a partir del año 1988 de un nuevo proceso de destrucción, de desmovilización y de fragmentación de los movimientos populares, en respuesta a embates de afuera y de adentro. Estos mecanismos, enunciados más arriba, fueron socavando las organizaciones sindicales y populares y nuestros ámbitos de trabajo en una suerte de "tener el enemigo adentro". Con una agravante anclado en nuestra historia de represión, sangre, muertes y desapariciones: la evocación constante en la población de los fantasmas de la represión y el miedo.

Comenzamos a conceptualizar estos fenómenos como multiples pobrezas: ${ }^{12}$ una pobreza de protección, una pobreza política y de participación, una pobreza de comprensión. Mas tarde, esta conceptualización nos fue teórica y dolorosamente fructífera para identificar y analizar el impacto que el neoconservadurismo del ajuste y la pobreza fue dejando en nuestra vida cotidiana. Nos referimos no sólo a la pobreza económica, sino también a una compleja realidad de pobrezas en plural. Éramos pobres de protección, de participación, pero ricos en miedo almacenado. Se necesitaba poco para abrir compuertas y que este miedo vuelva a aparecer (Sirvent, 1992).

${ }^{12}$ Las multiples pobrezas no se agotan en el diagnóstico de las carencias que hacen a la satisfacción de las necesidades tradicionalmente llamadas básicas u obvias, que ya no son tan obvias, tal como por ejemplo trabajo, vivienda, salud, educación, sino que abarca el estudio de una compleja realidad de pobrezas (en plural) en relación con carencias en la satisfacción de necesidades fundamentales, pero no tan obvias, como la necesidad de protección o cuidado, la necesidad de pensamiento reflexivo o de entendimiento y la necesidad de participación social y política. Cualquier necesidad humana que no es adecuadamente satisfecha socialmente revela una pobreza social y genera procesos de exclusión y de aumento de la violencia internalizada en las relaciones sociales, y puede generar patologías colectivas toda vez que rebasa límites de intensidad y duración. Este enfoque se centra en el análisis de las condiciones objetivas de una sociedad que facilitan o inhiben la satisfacción de estas necesidades para la mayoría de la población. Es una perspectiva social y psicosocial de análisis, y no individual. Para más detalles ver Sirvent (1998, 1999a, 2001). 
Fuimos así descubriendo objetivos específicos para nuestras acciones de investigación participativa y de educación popular de jóvenes y adultos, no sólo en el ámbito de las asociaciones barriales sino también en nuestros trabajos y talleres con docentes de la escuela de adultos:

a) el reconocimiento en nosotros y en los otros de las marcas de una historia social y política cruenta;

b) la reconstrucción de una memoria colectiva fragmentada y cercenada;

c) la identificación de los mecanismos institucionales, de los mecanismos de poder y las representaciones sociales que inhibían la posibilidad de un crecimiento en la participación social.

En este período aprendimos que el aprendizaje de la participación real es un largo y difícil proceso de aprendizaje; más largo y difícil que la apropiación de los conocimientos académicos necesarios para nuestra vida profesional y cotidiana. Fuimos viendo que los mecanismos antiparticipativos que habíamos aprendido se legitimaban y reproducían en la vida asociacional y cotidiana. Y eran muy difíciles de quebrar. Se iba consolidando en nuestros trabajos la profunda trama entre participación social y mecanismos de poder. Fuimos descubriendo en nuestras investigaciones la complejidad de esa relación que terminaba abortando los intentos participativos, ya sea "ahogando" las demandas colectivas consideradas peligrosas para el status quo (mecanismos de nodecisión), ${ }^{13}$ o bien por la "coaptación" de los líderes de un movimiento de resistencia o protestas.

Segundo momento: 1989-2001 Los años 1990 y el proceso de implementación y consolidación del neoconservadurismo

Dos aspectos van apareciendo en este contexto. Por un lado, la evidencia que nos permitió aseverar

${ }^{13}$ Ver referencia sobre el enfoque de la "tridimensionalidad del poder" en la nota al pie número 19. como hipótesis de trabajo que el neoconservadurismo en Argentina encontró una tierra arrasada, donde floreció sin muchos vendavales o nevadas. Que las condiciones de la sociedad argentina ya estaban dadas para la implementación del modelo neoconservador del ajuste y la pobreza, casi sin enfrentar una resistencia organizada.

Por el otro, un contexto que se iba perfilando cada vez más hostil a la participación social y a la educación popular. Y no sólo en la sociedad civil, sino también en el ámbito de la educación. Comenzamos a asistir en nuestros ámbitos académicos a un supuesto velatorio de la educación popular y de la participación. La "educación popular ha muerto...” “... la participación ha muerto...", escuchábamos decir en nuestras aulas universitarias. No fue fácil seguir trabajando y formando cuadros en educación popular. Habíamos pasado de un boom en el 1984, 1985, a ver nuestras aulas vacías a partir del 1989. Muchos intelectuales también, formadores de mentalidades nuevas, habían sido cooptados y habían devenido en "los intelectuales orgánicos" de la transformación educativa neoliberal. Algunos de nosotros, por el contrario, comenzamos, desde la implantación del neoliberalismo, a prever y a advertir sobre sus funestas consecuencias. Éramos tildados entonces de "los folklóricos y románticos del 1960. No nos fue fácil continuar con la formación de cuadros en educación popular en este contexto. Pero lo hicimos.

Y no era casualidad este contexto de riesgo para la participación. La noción de participación real entraba en franca contradicción con la filosofía política neoconservadora, como dicen sus espíritus rectores que plantean en sus escritos una lucha entre dos principios irreconciliables: el mercado y la organización popular. Se visualiza una "enemistad mortal" que no conoce camino intermedio. Evidentemente, miseria y libertad no son compatibles.

Varios son los fenómenos que agravaban la situación de múltiples pobrezas. Por un lado, la desocupación, el miedo a la pérdida de empleo agudizaba la pobreza de protección, el miedo a la sanción por el discenso, el miedo a la participación. La desocupación 
es uno de los mecanismos privilegiados de control social. Nos decían en nuestros trabajos los jóvenes y adultos frases tales como: " 14 Antes éramos explotados, ahora, peor que eso, nos tratan como ratas pero no podemos reaccionar... perdemos el empleo de ratas pero empleo al fin. Da de comer...". Estas expresiones son manifestaciones de violencia que generan sensaciones de desamparo y soledad.

Por el otro, la agudización de los factores inhibitorios ya detectados en el período anterior profundizaba la pobreza de participación. La agudización del individualismo y la crisis de participación, crisis de identidad colectiva, crisis de pertenencia, crisis de confianza y credibilidad, fragmentación, el "egoísmo", el clientelismo político, el accionar de los punteros políticos, el partidismo, la manipulación y coaptación por parte de los organismos de gobierno, herían la participación de la población en organizaciones formales. Aparecieron "las participaciones de emergencia", ${ }^{15}$ situaciones de reclamos colectivos en barrios y comunidades con objetivos a corto plazo, de poca duración en el tiempo (a veces pocas horas), que reproducían la fragmentación y los mecanismos de disolución de las tramas organizativas.

Se va consolidando el así llamado pensamiento único: una suerte de “... doctrina viscosa que insensiblemente envuelve cualquier razonamiento rebelde, lo inhibe, lo perturba, lo paraliza y acaba por ahogarlo". ${ }^{16}$ Nos referimos a una manera de "ver" o "analizar" la realidad por la cual, consciente o inconscientemente, se fue legitimando esta realidad regresiva, injusta y absurda, que vivimos como la que tenía que ser y no podía ser de otra manera. Se fue aceptando los "versos" del neoliberalismo, sin ver alternativas. Es el fenómeno de la naturalización de la injusticia, la explotación y la pobreza en las mentes de la población. Na-

${ }^{14}$ Frases extraídas del artículo de Sirvent (2001).

${ }^{15}$ Expresión atribuida por Sandra Llosa, miembro del equipo de trabajo en una investigación participativa realizada en la Ribera de Quilmes.

${ }^{16}$ En "Pensamiento crítico vs. pensamiento único". Le Monde Diplomatique, edición española (L-Press), 1998. turalización que agudizaba la pobreza de comprensión e inhibía el desarrollo de un pensamiento crítico. El poder dominante se fue transformando en nuestro sentido común. Se volvió natural lo que debió escandalizarnos. ${ }^{17} \mathrm{Ha}$ escrito al respecto un filósofo argentino:

Es el efecto del genocidio en nuestras mentes. [...] El terror no permite al ser humano adquirir conciencia de sí mismo... enmudece... aterra, y en ese sentido el nivel de percepción de la realidad está adecuado al miedo que produce, ver y decir cosas que no son toleradas por el Poder. Te divide la cabeza; no podés imaginar siquiera porque el imaginario viene de afuera y se mete en vos. (León Rozitchner; ${ }^{18}$ el destacado es nuestro)

Se fueron consolidando en nuestros trabajos conceptualizaciones del poder y sus mecanismos de dominación, en la complejidad de diversas formas de manifestarse ${ }^{19}$ y en relación con la conformación de

${ }^{17}$ Hernán Kesselman se preguntaba: ¿Cómo se vuelve natural lo que debiera escandalizarnos? En el Panel Inaugural de la III Jornada Latinoamericana de Psicología Social y V Jornada de Homenaje al Dr. Enrique Pichón Riviére, "Sujeto y conflicto social". Buenos Aires, 28 al 31 de Octubre de 2004.

${ }^{18}$ Trozos extraídos del pensamiento de León Rozitchner expresado en Página 12, de 22 de enero de 2001, y en entrevista en radio La Isla Buenos Aires Año 2000. Citado en Sirvent (2001).

${ }^{19}$ En este aspecto trabajamos con la noción de "tridimensionalidad del poder" presentada por Steven Lukes (1981). Desde esta perspectiva teórica, el poder se ejerce en tres dimensiones o de maneras diversas. En primer lugar, a través de la forma más manifiesta y expresa: el ejercicio de la toma de decisiones efectiva (una ley, una reglamentación, una orden) acompañado de la emisión de amenazas manifiestas o latentes para su cumplimiento. En segundo lugar, y de manera menos manifiesta y clara, el poder se ejerce a través de los procesos de no-decisiones que ahogan las demandas y reivindicaciones amenazantes para el orden establecido. La tercera forma de ejercicio del poder se desarrolla fundamentalmente a través de los procesos de aprendizaje social que inhiben el crecimiento de una cultura popular como campo de lucha por los derechos humanos y la justicia social y de una educación favorecedora de la formación de conciencias críticas de la sociedad. 
nuestras representaciones sociales, de nuestras maneras de pensar y teorizar cotidianamente sobre la realidad circundante. Desde esta perspectiva asumimos que la construcción de este pensamiento único, tal como fue caracterizado más arriba, es la resultante de mecanismos de poder que ya cientistas políticos en la década del 1980 señalaban como la forma más perversa de ejercicio de poder. Lukes (1981, p. 24-25) escribe:

¿No es la forma suprema y más insidiosa de ejercer poder, de cualquier grado, impedir que la gente vea las injusticias a través de la conformación de sus percepciones, conocimientos y preferencias, en tal sentido que acepten su rol en el orden existente de cosas. Ya sea porque ellos pueden no ver otra alternativa o porque ellos ven este orden como natural e incambiable o porque ellos lo evalúan como orden divino y beneficioso?

Nosotros estamos ocupados de encontrar como es ejercido el poder para prevenir a la gente de hacer y a veces aún de pensar. (La traducción y el destacado son nuestros).

La lucha social, la lucha de las clases sociales, se juega también en el campo de la cultura cotidiana, entendiendo ésta como un campo de lucha entre significados diferentes y a veces contradictorios del mismo fenómeno. Es la lucha por la apropiación de la llave del código. ${ }^{20}$ La lucha de clases se juega en cómo pensamos la realidad, en la manera como nominamos, a través del lenguaje, a los fenómenos de nuestra vida cotidiana; se juega en el mundo de los significados que le atribuimos a nuestro entorno cotidiano. En su trabajo, “Distinción”, Bourdieu (1984, p. 479-480) dice:

Esta noción de tridimensionalidad del poder nos parece de una notable fertilidad teórica para describir e interpretar varios fenómenos de nuestra realidad cotidiana. En nuestros trabajos citados anteriormente (Sirvent, 1999, 2001) se encontrarán ilustraciones cotidianas de estos mecanismos de poder.

${ }^{20}$ Frase de Diana Weshler desde su perspectiva de una sociología del arte. Clases en la Universidad de La Plata. Provincia de Buenos Aires - Argentina.
Lo que está en la mira, en la lucha sobre el significado del mundo social, es el poder sobre los esquemas y sistemas clasificatorios, que están en las bases de las representaciones de grupos y por tanto de su movilización y desmovilización...

En este contexto, nos planteamos como objetivos de nuestras investigaciones y acciones de educación popular generar espacios de análisis de esta compleja realidad de desempleo y mecanismos de poder para:

a) enfrentar la tendencia a naturalizar la realidad como la única posible. Como lo que tienen que ser... y que no puede ser de otra manera;

b) enfrentar la tendencia a convertirse de víctimas en victimarios; es decir, en culpables de su propia situación. Estas frases de nuestras investigaciones ilustran dramáticamente este aspecto:

Ya no salgo a buscar trabajo ¿Para qué? Me amargaba. Cada vez que salía volvía con las manos vacías y ya no me daba para enfrentar las caritas y los ojos de mis hijos como diciéndome: Papá, vos tenés la culpa. Bueno ahora me pueden culpar de no buscar pero no de no encontrar. (35 años obrero de la construcción )

Yo era camionero hasta que me echaron. Hacía viajes al interior y también a Brasil y a Chile. Ahora no sé qué hacer... estoy cansado. No puedo mirar a mis hijos a la cara. Yo ya no quiero nada. Quiero irme a otro país a ver si en otro lado las cosas están mejor. Ya no tengo ganas ni de ir a votar (33 años)

c) enfrentar la tendencia a encontrar chivos emisarios culpables de la situación de miseria y pobreza, como los bolivianos y paraguayos, agudizando la fragmentación social. Como se expresa en estas frases obtenidas en nuestros trabajos:

Yo estudié y estoy manejando un taxi; la culpa la tiene esos paraguayos y bolivianos indocumentados que nos sacan el trabajo. La Argentina es para los argentinos. Habría que matarlos a todos. 
El culparse a sí mismo, o el culpar a los imigrantes del más del $20 \%$ de nivel de desempleo, encubre el análisis de las causas estructurales del desempleo.

d) identificar los mecanismos de poder, especialmente los más sutiles, para enfrentarlos.

Estos objetivos implicaron fundamentalmente trabajar en lo que denominamos el "talón de Aquiles" del pensamiento único (Sirvent, 2001). Este pensamiento único, este ejercicio tan perverso del poder, se conforma a través de procesos de aprendizajes formales y no-formales. La construcción de este pensamiento es la resultante de mecanismos de poder que operan a través de procesos de educación, de aprendizaje; no es algo genético. Por tanto la educación dentro o fuera de la escuela puede ser instrumento de reforzarlo o desbaratarlo. Lo que se construye, se desconstruye.

Paralelamente, veíamos el surgimiento de nuevas fuerzas: trabajadores desocupados, poblaciones sumidas en la pobreza y en la pobreza extrema, los piqueteros, grupos que iban apareciendo con picos de crecimiento y de decrecimiento. Diversos sujetos en todos los sectores aplastados, expoliados por el capital. Teníamos la expectativa que aquí desde estas bases se estaba gestando tal vez los nuevos sepultureros del neoliberalismo, y que debíamos de alguna manera apoyar desde nuestras acciones de educación popular el avance hacia una articulación mayor. Pero sólo una visión fugaz... Con algunos de sus representantes, por ejemplo, comenzábamos a hablar de intentar colectivamente una investigación histórica sobre la destrucción del movimiento villero para descubrir las fuerzas que llevaron a su destrucción y enfrentarlas para no repetirlas...

\section{Tercer momento:}

\section{diciembre 2001- hasta el presente actual}

A partir de los sucesos del 19 y 20 de diciembre del $2001^{21}$ en Argentina, nuevamente la realidad

${ }^{21}$ El 19 y 20 de diciembre de 2001 fue la culminación de un proceso de varios días que desencadenó la renuncia del entonces sorprende y desafía todos los más exquisitos pronósticos de los científicos sociales.

Nos enfrentamos con una serie de situaciones nuevas en el campo de lo social que hubieran sido difíciles de prever hacia fines del año 2001.

Fueron varias las manifestaciones de protesta popular y de emergencia de movimientos sociales que comenzaron a desafiar la imposición del pensamiento único y ha producir una ruptura en la aceptación sumisa y "naturalizada" de la injusticia social y la pobreza, y fundamentalmente del miedo acumulado en años de represión política y de cruentas dictaduras militares.

Como varias veces hemos señalado en trabajos anteriores, las necesidades humanas son claras evidencias de la tensión constante entre carencia y potencia característica de los seres humanos (Sirvent, 1999a) y devienen, en determinados momentos históricos, en impulsos para la acción; en este caso, en acción colectiva donde se buscaba una nueva organización social y la construcción de un nuevo conocimiento.

Como investigadores sociales, estábamos ante un contexto social que desafiaba nuestro conocimiento, nuestros interrogantes y el sentido de nuestra tarea de descubrimiento. Cuando, hacia fines del año 2001, hablábamos de catástrofe social y de patologías

presidente de la nación, Dr. Fernando de la Rúa, y todo su gabinete. En la noche del 19 de diciembre, en respuesta al estado de sitio decretado por el gobierno, se congregaron miles de argentinos en distintas plazas y calles del país, sobre todo en Capital Federal, donde una multitud de personas de los diversos barrios de la ciudad de Buenos Aires salieron "caceroleando" por las calles y llegaron hasta Plaza de Mayo. Desde estos sucesos comenzaron a generarse en Capital Federal y todo el país asambleas barriales constituidas por una diversidad de sectores sociales. A partir de estas manifestaciones se constituyen nuevas formas de expresión de la protesta popular y de búsqueda de instancias alternativas de participación social, y se consolidan otras formas nuevas de organización popular que ya venían desarrollando su historia, como la de los movimientos piqueteros, conformados principalmente por trabajadoras y trabajadores desocupados. 
colectivas, surgían nuevas formas de protesta social $\mathrm{y}$ de movimientos sociales que desafiaban nuestras categorías teóricas y nos introducían en un nuevo tiempo histórico. Nuevamente la realidad nos fascinaba con lo más preciado del sentir científico: la ignorancia, la duda, la incertidumbre.

Desde una concepción totalizadora de educación permanente que trasciende la escuela y abarca todos los aprendizajes sociales a lo largo de la vida de una población, debíamos intentar develar e introducirnos en profundidad en estos procesos de aprendizaje social y de educación popular que se estaban dando en los nuevos movimientos sociales en Argentina. ¿Qué se aprende? y ¿Cómo se aprende? son preguntas que emergían a cada momento en nuestro trabajo cotidiano, buscando por respuestas científicas que apoyaran acciones de fortalecimiento del impacto educativo de la participación y la militancia social.

Vivimos una cultura popular y cotidiana donde se confrontan, se tensionan con agudeza, por un lado, las fuerzas de la resistencia y de la creatividad popular, y por el otro las fuerzas de la aceptación y el sometimiento. Es el campo de la cultura popular percibido como uno de los escenarios de la lucha a favor y en contra de una cultura de los poderosos. Es la cultura popular analizada como el ruedo del consentimiento y la resistencia creativa. ${ }^{22}$ Esta complejidad se nos aparece en nuestro día a día.

Por un lado se vive una suerte de despertar a la participación y a la conciencia de nosotros como

${ }^{22}$ Stuart Hall (1981) escribe que lo esencial para la definición de la cultura popular son las relaciones que definen a la "cultura popular" en tensión continua (relación, influencia y antagonismo) con la cultura dominante Para Stuart Hall, el análisis que debe hacerse es el análisis de la lucha de clases en la arena cultural: "De otra manera, si he de decirles la verdad, la cultura popular me importa un pito. [...] La cultura popular es uno de los escenarios de esta lucha a favor y en contra de una cultura de los poderosos; es también lo que puede ganarse o perderse en esa lucha. Es el ruedo del consentimiento y la resistencia. Es en parte el sitio donde la hegemonía surge y se afianza.” (p.239). sujetos históricos; las asambleas populares, los piqueteros, el movimiento de trabajadores desocupados, las tomas de fábricas desocupadas y cerradas fueron y pueden seguir siendo expresiones de una potencial explosión de una futura organización.

Pero, por otro lado, los fantasmas de la fragmentación, el clientelismo, la coaptación siguen actuando, legitimados y prontos para debilitar el movimiento popular.

Deseo remarcar los aspectos siguientes:

a) Hay signos y pistas muy fuertes de ruptura del abroquelamiento del pensamiento único. En uno de los documentos del Movimiento Barrios de Pie se dice con relación a las acciones de educación popular del Movimiento: "[...] la educación popular [...] es desnaturalizar este modelo injusto de dominación, hambre y pobreza".

b) Aparecen evidencias de un reconocimiento de necesidades no tan obvias como la necesidad de participación. Así se expresaba un miembro de una Asamblea Barrial haciendo referencia al momento de emergencia de las Asambleas Barriales, a fines del año 2001, principios del $2002: 23$

La sensación general era: "Esto no da para más". No le creemos a nadie. Nos cagaron la vida. Algo hay que hacer. Tenemos que tomar las cosas en nuestras manos. Hoy rescato de eso el reconocimiento general que hubo de la necesidad de participación por parte de la gente, activamente, digo. Se vio la experiencia acumulada de mucha gente que en los 90 durante el menemismo habia estado "metidos para dentro"... Lo que más me llamaba la atención era el sentir general de que si no nos involucramos nos van a seguir cagando. Hay que

${ }^{23}$ Entrevista realizada por los alumnos de la carrera de Ciencias de la Educación de la Universidad de Buenos Aires, en el marco de la cátedra coordinada por María Teresa Sirvent, año 2004 . 
buscar los puntos neurálgicos. Uno veía como todo afloró. Hay que participar activamente. Si no nos metemos, nos van a seguir cagando. "La lucha forma parte de nuestro modo de vida".

c) Se identifican evidencias de un crecimiento en el reconocimiento del proceso educativo en el espacio de la lucha y el movimiento social. Aparecen evidencias de fenómenos nuevos en el campo educativo de los movimientos sociales. Se percibe, por un lado, un reconocimiento explícito de la importancia de la educación y del lugar de la educación en su proceso de lucha y de organización. Como expresó el Movimiento de Barrios en Pie: Hemos aprendido mucho en esa gran escuela que es la lucha en las calles. ${ }^{24}$

Por otro lado, aparece una demanda social y educativa $^{25}$ y la realización concreta de instancias formales de educación alternativa dirigidas a la infancia, la adolescencia y los adultos en situación de pobreza educativa, ${ }^{26}$ a cargo de los protagonistas de los movimientos sociales y “... con la impronta del movimien-

${ }^{24}$ Segundo Plenario del Movimiento Barrios de Pie 25 a 27 de Octubre 2002.

${ }^{25}$ Demanda social es la expresión organizada y colectiva de necesidades y reivindicaciones que los miembros de un grupo social buscan implementar a través de decisiones institucionales y/o públicas. En nuestros trabajos hemos desarrollado la perspectiva de construcción social, histórica y colectiva de una demanda social como producto de la acción colectiva de un grupo. El concepto de demanda social debe ser entendido como las necesidades definidas por clase social, fracciones de clase, organizaciones, grupos e inclusive individuos estratégicamente situados frente al Estado. Esta perspectiva de la demanda social nos introduce al ámbito de las relaciones Estado y Sociedad Civil en una perspectiva de una sociología política de la educación permanente. Para más detalle, ver Sirvent (1999b).

${ }^{26}$ La pobreza educativa no se limita al porcentaje de analfabetos, sino que abarca el $67 \%$ de población económicamente activa de 15 años y más que ya no está en la escuela y que se encuentra en to". ${ }^{27}$ Son proyectos educativos de diversa naturaleza, generados por los integrantes de los movimientos sociales. Como por ejemplo: espacios de alfabetización, talleres de educación popular, apoyo escolar, jardines de infantes, escuelas etc. Los protagonistas

situación educativa de riesgo. Son 14.015.871 (Censo 2001) de jóvenes y adultos condenados a un probable futuro de marginación social, política y económica agudizado por el contexto de múltiples pobrezas. Son aquellos que alguna vez se matricularon en la escuela primaria y que abandonaron su camino sin haber logrado los niveles básicos de educación formal necesarios para enfrentar la complejidad social, política y económica de la sociedad actual. Sólo alcanzaron un nivel de primaria incompleta, o primaria completa, o "con suerte", los menos, algunos peldaños de la educación media. Para la franja de jóvenes de 15 a 24 años las cifras son graves: el $71 \%$ se encuentra en situación educativa de riesgo. Esta situación se agrava para aquellos provenientes de hogares pobres. El censo de 1991 mostraba que en dichos grupos más del $90 \%$ de los jóvenes y adultos mayores de 15 años estaban en situación educativa de riesgo. Este dato se incrementa si se tiene en cuenta el aumento de la población en situación de pobreza y de pobreza extrema de la última década. El censo del 2001 mostraba en el Gran Buenos Aires un 93\% de jóvenes de 15 a 19 años provenientes de hogares pobres en situación educativa de riesgo. Asimismo, el censo del 2001 muestra que la brecha del crecimiento del nivel educativo entre pobres y no pobres ha aumentado. El nivel educativo de riesgo refiere al fenómeno de discriminación e injusticia en que vivimos. No se trata de una cuestión de déficit individual, sino de exclusión social y represión que se agrava por ser muy bajo el porcentaje de esta población (entre el $2 \%$ y el $5 \%$ según regiones del país) que ha podido insertarse en experiencias de educación de jóvenes y adultos que les permitan superar estas carencias educativas. Estos datos provienen de una investigación que, con la dirección de María Teresa Sirvent, se está realizando desde el año 1997 en Capital Federal, Gran Buenos Aires, Córdoba e Entre Ríos.

${ }^{27}$ Expresiones de la exposición de miembros de movimientos sociales en un panel de diálogo de la Conferencia Internacional de Sociología de la Educación (International Sociological Asociation/Facultad de Filosofía y Letras, Universidad de Buenos Aires, Agosto 2004) 
expresan:28 “... el acto más valioso es el hecho educativo"; "Si hay algo que fortaleció fue la educación, el ir pensando entre todos los espacios educativos"; "Lo más interesante es pensarlo todos juntos"; "El objetivo del taller es construir la voz de los más humildes"; "No podemos pensar el espacio de educación popular fuera de la lucha".

Va creciendo en los protagonistas de los movimientos sociales el reconocimiento del saber propio y de la capacidad de construcción colectiva de conocimiento. ${ }^{29}$ Así lo expresan: “... se cae el muro del que el saber está en un solo lugar; está en todos nosotros"; “... reflexionamos, hacemos categorías, construimos esos cajoncitos que es en definitiva hacer teoría".

Un conocimiento que entre otras cosas se ha convertido en un instrumento de lucha contra figuras perversas, como la de la víctima convertida en victimario, que, como señalamos más arriba, se atribuye a si misma la culpabilidad de la desocupación y que paraliza cualquier acción colectiva. El título de un libro del Movimiento de Trabajadores Desocupados (MTD) de la Matanza ${ }^{30}$ es una clara ilustración de lo que estamos señalando: De la culpa a la autogestión. Este libro, que los protagonistas mencionan como una construcción intelectual del MTD, está mostrando un proceso histórico de construcción de un nuevo conocimiento; de nuevas categorías de interpretar la realidad del desempleo como un fenómeno estructural y no individual. Un proceso de apropiación de los medios de producción simbólica, como así lo expresan los mismos miembros del Movimiento. ${ }^{31}$ Se concibe al movimiento social como sujeto pedagógico.

\footnotetext{
${ }^{28}$ Idem.

${ }^{29}$ Idem.

${ }^{30}$ Localidad del Gran Buenos Aires.

${ }^{31}$ Ponencia de Soledad Bordegaray, integrante del MTD de
}

La Matanza en la Conferencia Internacional de Sociología de la Educación (International Sociological Association/Facultad de Filosofía y Letras, Universidad de Buenos Aires, Agosto 2004).

\section{Desafíos y contradicciones del momento histórico presente para la educación popular de jóvenes y adultos en su relación con los movimientos sociales emergentes}

Nos preguntamos: ¿Cómo potenciar esta fuerza creativa en un crecimiento de la capacidad de demanda social de los movimientos sociales por su derecho a una educación pública igualitaria y de calidad en manos del Estado?

Esta fuerza creativa, en sus luchas y contradicciones, debe ser apoyada y fortalecida, pues por el otro lado los fantasmas acechan. Como señalamos más arriba, los factores obstaculizadores de la participación, señalados e identificados en los momentos históricos anteriores a través de nuestras investigaciones, no se han vencido de la noche a la mañana. Hoy observamos su fuerte presencia en nuestros trabajos.

La represión no se ejerce solamente con la fuerza y la coacción física. La voluntad de lucha y de acción colectiva se ve amenazada también por los intentos de coaptación de los líderes de los movimientos sociales o por planes de subsidio a los trabajadores desocupados que pretenden por un lado ser un paliativo a la pobreza y a la pobreza extrema, pero por el otro fragmentan, desunen y debilitan la participación social. Los líderes de las asociaciones populares tradicionales se sienten impotentes frente a un debilitamiento de la participación social que se contrapone en forma manifiesta con la acción colectiva de los nuevos movimientos sociales. Sin embargo, también el fenómeno de la fragmentación aparece invadiendo tanto a las asociaciones populares tradicionales como a los nuevos movimientos sociales emergentes.

Sigue vigente el mecanismo de la fragmentación como un estigma de nuestra historia social o el de la coaptación de líderes por parte de instituciones gubernamentales o privadas que operan en el debilitamiento de la fuerza de lucha del movimiento social.

Por otra parte, se ha agudizado, en los sectores sumidos en situaciones de pobreza y de pobreza extrema, la situación de desesperanza y miedo reflejada en la imagen de una juventud condenada al fracaso y a la 
muerte y en la amenaza que reciben los líderes barriales de las instituciones vecinales cuando desean enfrentarse al puntero político o al "diller” del narcotráfico. En una reunión de análisis colectivo de la realidad con vecinos y miembros de organizaciones populares de una villa miseria de Capital Federal, se nos decía: "La juventud está más desprotegida que nunca. Cuando el joven no le interesa más al dirigente, al narco, es 'boleta'. Ahora van a morir. Ahora los mata".32

Los mecanismos de poder siguen actuando sobre la construcción de categorías del pensar la realidad que buscan descalificar ante la población a los movimientos sociales y especialmente el movimiento piquetero. Esta descalificación actúa como mecanismo de poder trabajando sobre el miedo de la población para debilitar y ahogar las demandas sociales percibidas como riesgosas para el establishment e intentando debilitar el fortalecimiento de la organización popular. No es casual que en nuestros trabajos una entrevistada nos haya expresado: "Yo nunca digo que soy desocupada. De lo contrario, enseguida me dicen: Ah! sos desocupada, entonces sos piquetera! Por eso ya no digo más que soy desocupada".

Este juego de factores contradictorios se desarrolla en un contexto de múltiples pobrezas.

Se asume que el educador, el investigador comprometido socialmente, debe apoyar en este momento histórico a los grupos de los nuevos movimientos sociales que pueden constituirse en los futuros sepultureros de un modelo de sociedad injusta y discriminatoria.

Esto implica poner los instrumentos de la ciencia y de la educación al servicio de la construcción de un conocimiento científico colectivo que ayude a fortalecer la organización y la capacidad de participación social de los nuevos movimientos sociales emergentes; que potencie la consolidación de una demanda social por la satisfacción de las necesidades obvias y no tan obvias. Entre ellas, una demanda social que enfrente la realidad de una profunda situación educa-

\footnotetext{
${ }^{32}$ De reunión realizada en la Villa 15 de Capital Federal.
}

tiva de riesgo para la mayoría de la población y que reivindique la necesidad y el derecho de una política educativa que otorgue prioridad a la educación permanente de jóvenes y adultos. Que fortalezca los procesos de aprendizaje social y la identificación de nuevas necesidades educativas y su conversión en demandas sociales por un aprendizaje permanente a lo largo de toda la vida.

Para ello es necesario generar conocimiento colectivo sobre situaciones problemáticas que necesitan indagación; conocimiento científico sobre preguntas que demandan el instrumental de la ciencia para contestarlas; conocimiento científico que apuntale la acción enfrentando las contradicciones sociales que nos ahoga; fortaleciendo los componentes de la resistencia y de la creación popular, y modificando los componentes de formas naturalizadas de comportamientos cotidianos que fracturan y fragmentan la organización social.

Desde nuestra perspectiva teórica y metodológica, consideramos que estas preguntas deben emerger de un trabajo colectivo con los movimientos sociales, y no solamente desde el escritorio de los investigadores y profesionales de la educación; que deben ser compartidas con los actores sociales y que el conocimiento generado debe ser una clara trama que articule dialécticamente el conocimiento cotidiano con el saber científico.

En este sentido, los principios epistemológicos, teóricos y metodológicos compartidos por una educación popular de jóvenes y adultos y la Investigación Ación Participativa (IAP) son consistentes con estas intencionalidades y se apoyan en los conceptos básicos del paradigma de la teoría social crítica.

Desde nuestra perspectiva, el objetivo central de la educación popular de jóvenes y adultos de crear conciencia puede potenciarse, fortalecerse y consolidarse con la introducción del componente de investigación social para construir una ciencia emancipatoria, un conocimiento científico emancipatorio puesto al servicio de la construcción del proyecto político de los sectores populares que desde la resistencia buscan crear nuevas formas de organización social. Y 
para ello las herramientas de la investigación social puestas al servicio de la educación popular de jóvenes y adultos y de la lucha del pueblo por su liberación pueden ser fértiles y fructíferas... y si no lo son, no son nada.

Quisiera terminar con una frase de José Martí: "De pensamiento es la guerra mayor que se nos hace; ganémosla a pensamiento."

MARÍA TERESA SIRVENT, doutora en filosofía por la Columbia University, New York, USA, es profesora titular del Departamento de Ciencias de la Educación, en la Facultad de Filosofía y Letras de la Universidad de Buenos Aires (UBA) y Investigadora del Consejo Nacional de Investigaciones Científicas y Técnicas (CONICET), en el Instituto de Investigaciones en Ciencias de la Educación de la Facultad de Filosofía y Letras de la UBA. Recebió la Beca John Simon Guggenheim Memorial Foundation, en 1996. Autora de libros y artículos sobre sus experiencias en investigación y participación social, educación y cultura popular en Argentina y en Brasil. Entre sus publicaciones recientes se encuentran Cultura popular y participación social: una investigación en el barrio de Mataderos - Buenos Aires (Editorial Universidad de Buenos Aires / Facultad de Filosofía y Letras y Miño y Dávila, 2. ed., 2004); La investigación social y el compromiso del investigador: contradicciones y desafíos del presente momento histórico en Argentina (Cahiers des Amériques Latines, 42 Dossier Terrains d’Enquete 2003, p. 81-100. Nueva versión en Revista del Instituto de Ciencias de la Educación n. 22, Editorial Miño y Dávila). Sus experiencias en Brasil se encuentran, en portugués: Educação comunitária: a experiência do Espírito Santo (São Paulo: Brasiliense, 1984), y en español: Educación de adultos: investigación y participación; desafíos y contradicciones (Buenos Aires: Editorial Coquena, 1994). Su línea de investigación se focaliza en el estudio de las relaciones entre Estructura de Poder, Participación Social y Cultura Popular, en el área de la Educación de Jóvenes y Adultos de los Sectores Populares. E-mail: msirvent@ciudad.com.ar

\section{Referências bibliográficas}

BOURDIEU, Pierre, (1984). Distinction: a social critique of the judgement of taste. Massachusetts: Harvard University Press, 1984.
HALL, Stuart, (1981). Notes on deconstructing "the popular". In: SAMUEL, Raphael (ed.). People's history and socialist theory. London: Routledge and Kegan Paul, p. 227-241.

LUKES, Steven, (1981). Power: a radical view. London: The MacMillan Press, 1981. Traducción española-Madrid: Siglo XXI, 1985.

SIRVENT, María Teresa, (1992). ¿Qué está pasando con la educación? Nueva Tierra, año 6, n. 8, ago., p. 5-10.

, (1998). Multipobrezas, violencia y educación. In: IZAGUIRRE, Inés (coord. y comp.). Violencia social y derechos humanos. Buenos Aires: Editorial EUDEBA, p. 201-209.

(1999a). Cultura popular y participación social. Una investigación en el barrio de Mataderos (Buenos Aires). Buenos Aires/Madrid: Editorial Facultad de Filosofía y Letras/ Miño y Dávila. Versión en español: SIRVENT, M. T., (1995). Participatory research on established order, popular culture, and engagement of the working classes in Buenos Aires. Ph.D. Dissertation, Columbia University, New York. Michigan UMI Dissertation Services, A Bell and Howell Company.

(1999b). The potential, actual and social demand for adult learning in Argentina: the situation of educational risk and cumulative advantage. In: SINGH, Madhu (ed.). Adult learning and the future of work. Hamburgo, Germany: UNESCO, Institute for Education, p. 143-167.

, (2001). El valor de educar en la sociedad actual y el "Talón de Aquiles" del pensamiento único. Voces, Asociación de Educadores de Latinoamérica y el Caribe, año 5, n. 10, nov., p. 5-13 (Circulación Internacional).

, (2003). Educación popular de jóvenes y adultos y participación social: una historia y un presente. Temas em Educação, João Pessoa, Editora Universitária UFPB, n. 12, p. 221-238.

(2004). Organización, poder y conocimiento: contribuciones de la investigación participativa a la educación popular. In: Nuestra cabeza piensa donde nuestros pies caminna. Area de Educación Popular - Movimiento Barrios de Pie., p. 57-64. 


\section{Resumos/Abstracts}

\section{María Teresa Sirvent}

La educación de jóvenes y adultos frente al desafío de los movimientos sociales emergentes en Argentina

Situa historicamente a educação popular de jovens e adultos na Argentina, em relação aos movimentos sociais, a partir do fim da ditadura militar, em 1973, até os dias atuais. Analisa as dificuldades teóricas para entender as limitações subjacentes à participação social, decorrentes do período ditatorial, assim como os desafios e as contradições do momento presente.

Palavras-chave: educação de jovens e adultos; movimentos sociais; Argentina

\section{Adult and Youth Education and the challenge represented by the emerging social movements in Argentina}

This article situates popular and youth education in Argentina in its historical context, with relation to the social movements, from the end of the military dictatorship in 1973 up to the present day. It analyses the theoretical difficulties in understanding the limitations underlying social participation, resulting from the period of the dictatorship, as well as the challenges and contradictions of the present moment.

Key-words: adult and youth education; social movements; Argentina. 